\title{
Sodium tri(pyrazol-1-yl)-germanate and -stannate: New Tridentate Claw-ligands' containing group 14 metals
}

Alexander Steiner and Dietmar Stalke*

Institut für Anorganische Chemie der Universität Göttingen, Tammannstrasse 4, D-37077 Göttingen, Germany

$\left[(\text { thf })_{3} \mathrm{Na}\left\{(\mathrm{pz})_{3} \mathrm{Ge}\right\}\right] 1$ and $\left[(\mathrm{thf})_{2}(\mathrm{pz} \mathrm{H}) \mathrm{Na}\left\{(\mathrm{pz})_{3} \mathrm{Sn}\right\}\right]_{2} 2$ (pz = pyrazol-1-yl) are obtained by the reaction of pzNa with $\mathrm{GeCl}_{2}$.dioxane and $\mathrm{SnCl}_{2}$, respectively, in a $3: 1$ molar ratio in thf (thf = tetrahydrofuran); the X-ray structure determination shows that the $\left[(\mathrm{pz})_{3} \mathrm{Ge}\right]-$ unit in 1 is a tridentate ligand to the sodium, while the $\left[(\mathrm{pz})_{3} \mathrm{Sn}\right]-\mathrm{unit}$ in 2 is only bidentate resulting in dimerisation to produce overall a twelve-membered ring system.

Germanium(II) and tin(II) compounds are well known as acid-base systems and undergo a wide spectrum of reactions. The metal centre can either interact with electrophiles because of the free electron pair ${ }^{1,2}$ or with nucleophilic reagents to saturate its coordination sphere. ${ }^{3,4}$ Mixed-metal complexes containing germanium, tin or lead are known e.g. alkoxides of the composition $\mathrm{M}\left(\mathrm{OBu} \mathrm{u}_{3} \mathrm{E}(\mathrm{E}=\mathrm{Ge}, \mathrm{Sn}\right.$ and $\mathrm{Pb} ; \mathrm{M}=$ alkali metals, earth alkali metals, In, $\mathrm{Tl}$ and $\mathrm{Pb}) .{ }^{5}$ Heteroaromatic functions such as pyridyl or pyrazolyl should also be promising substituents for the formation of mixed-metal complexes. Recently we reported the synthesis and structure of dimethylaluminiumdi(2-pyridyl)phosphide, in which the pyridyl rings 
separate the two main group elements. ${ }^{6}$ Poly(pyrazol-1-yl)alkanes, borates and gallates are well known as nitrogen donor ligands for metal complexes. ${ }^{7-9}$ We aimed to replace the central atom of these ligands with group 14 metals like germanium, tin or lead. The reaction of EII-halides with, for example, alkali metal or alkali earth metal pyrazol derivatives in excess, should lead to complexes in which the resulting $(\mathrm{pz})_{2} \mathrm{E}^{\mathrm{Il}}$ unit interacts with an excess $(\mathrm{pz}) \mathrm{M}^{\mathrm{I}}$ or $(\mathrm{pz})_{2} \mathrm{M}^{\mathrm{II}}$ unit as an acid-base adduct. The donor ability of the 2-nitrogen atoms in the pyrazol substituents features the central metal three coordinated.

Here, we report the structures of sodium-tri(pyrazol-1-yl)germanate and -stannate, in which the pyrazolyl substituents bridge the alkali metal and the germanium or tin atom, respectively. The reaction of pyrazolylsodium, prepared from $\mathrm{NaH}$ and pyrazol in toluene, with $\mathrm{GeCl}_{2}$. dioxan and $\mathrm{SnCl}_{2}$, respectively, in a $3: 1$ molar ratio in tetrahydrofuran at $-78^{\circ} \mathrm{C}$ yielded pale yellow gels. The resulting $\mathrm{NaCl}$ could be separated by treating the mixtures with $n$-hexane.

Suitable crystals of $\mathbf{1} \dagger$ and $2 \dagger$ could be obtained after storage of the filtered solutions at $-18^{\circ} \mathrm{C}$ for $3 \mathrm{~d}$. The colourless crystals of both compounds decompose instantaneously at room temperature, because they rapidly lose solvent. The crystals were selected and transferred to the diffractometer at $-30^{\circ} \mathrm{C} .{ }^{10}$

1 Is monomeric in the solid state (Fig. 1). $\$$ The molecule adopts a threefold symmetry. The germanium and the sodium atom are located on the threefold axis and are connected via three pyrazol rings, demonstrating that the sodium cation as a hard Lewis-acid prefers the hard 2-nitrogen atoms rather than the softer germanium base. In the substituent separated contact ion pair the $\left[(\mathrm{pz})_{3} \mathrm{Ge}\right]^{-}$unit forms a tridentate claw gripping around the sodium atom, which is furthermore coordinated by three thf molecules. The $\mathrm{Ge}(1)-\mathrm{N}(1)$ distance is $196.5(6) \mathrm{pm}$ and the $\mathrm{N}-\mathrm{Ge}-\mathrm{N}$ angle $96.2(3)^{\circ}$. Similar structure patterns are found in the tri(pyrazol-1-yl)borates,

+ Spectral data for 1: ${ }^{1} \mathrm{H}$ NMR $\left\{250 \mathrm{MHz}, \mathrm{C}_{6} \mathrm{D}_{6},\left[{ }^{2} \mathrm{H}_{8}\right]\right.$ thf, $\mathrm{SiMe}_{4}$ (ext.) $\}: \delta 1.48(4 \mathrm{H}$, thf $), 3.51(4 \mathrm{H}$, thf $), 6.16\left(\mathrm{t},{ }^{3} J 1.8 \mathrm{~Hz}, 1 \mathrm{H}, 4-\mathrm{H}\right)$, $7.55\left(\mathrm{~d},{ }^{3} \mathrm{~J} 1.8 \mathrm{~Hz}, 2 \mathrm{H}, 3-\mathrm{H}, 5-\mathrm{H}\right) ;{ }^{119} \mathrm{Sn}$ NMR $[150 \mathrm{MHz}$, thf, $n$-hexane, $\mathrm{C}_{6} \mathrm{D}_{6}, \mathrm{SnMe}_{4}$ (ext.)]: $\delta-286 ; 2$ : ${ }^{1} \mathrm{H}$ NMR $\left[250 \mathrm{MHz}, \mathrm{C}_{6} \mathrm{D}_{6}\right.$, $\left[{ }^{2} \mathrm{H}_{8}\right]$ thf, $\mathrm{SiMe}_{4}$ (ext.)]: $\delta 1.49(8 \mathrm{H}$, thf $), 3.51(8 \mathrm{H}$, thf $), 6.17\left(\mathrm{t},{ }^{3} J\right.$ $1.9 \mathrm{~Hz}, 4 \mathrm{H}, 4-\mathrm{H}), 7.53\left(\mathrm{~d},{ }^{3} \mathrm{~J} 1.9 \mathrm{~Hz}, 8 \mathrm{H}, 3-\mathrm{H}, 5-\mathrm{H}\right), 12.32(\mathrm{~s}, 1 \mathrm{H}$, $\mathrm{N}-\mathrm{H})$.

$\ddagger$ Crystal data for $1[153(1) \mathrm{K}]: \mathrm{C}_{21} \mathrm{H}_{33} \mathrm{GeN}_{6} \mathrm{NaO}_{3} \cdot \mathrm{C}_{4} \mathrm{H}_{8} \mathrm{O}, M=513.1$, trigonal, space group P31c, $a=1302.1(1), c=1016.3(1) \mathrm{pm}, U=$ $1.4923(3) \mathrm{nm}^{3}, Z=2, D_{\mathrm{c}}=1.302 \mathrm{Mg} \mathrm{m}^{-3}, \mu=1.080 \mathrm{~mm}^{-1}, 4834$ measured reflections, 1302 independent, 1301 employed in the refinement, $2 \theta_{\max }=45^{\circ}, R 1=\Sigma\left|F_{0}-F_{\mathrm{c}}\right| \Sigma F_{\mathrm{o}}=0.042(F>4 \sigma F)$ and $w R 2=\left[\Sigma w\left(F_{\mathrm{o}}^{2}-F_{\mathrm{c}}{ }^{2}\right)^{2 / \Sigma} w F_{\mathrm{o}}{ }^{4}\right]^{\frac{1}{2}}=0.119$ (all data) of $w^{-1}=\sigma^{2}\left(F_{\mathrm{o}}{ }^{2}\right)+$ $(g 1 \cdot P)^{2}+g 2 \cdot P$ with $P=\left(F_{0}{ }^{2}+2 F_{\mathrm{c}}{ }^{2}\right) / 3$ and $g 1=0.079, g 2=0.0$, $\max$ residual density: $2.03 \times 10^{2} \mathrm{e} \mathrm{nm}^{-3}$.

For 2 [193(1) $\mathrm{K}]: \mathrm{C}_{40} \mathrm{H}_{58} \mathrm{~N}_{16} \mathrm{Na}_{2} \mathrm{O}_{4} \mathrm{Sn}_{2}, M=1110.4$, monoclinic, space group $P 2_{1} / c, a=1184.4(3), b=1696.7(4), c=1272.9(4) \mathrm{pm}, \beta$ $=92.57(3)^{\circ}, U=2555.4(1) \mathrm{nm}^{3}, Z=2, D_{\mathrm{c}}=1.443 \mathrm{Mg} \mathrm{m}^{-3}, \mu=$ $1.048 \mathrm{~mm}^{-1}, 4424$ measured reflections, 3327 independent, which were all employed in the refinement, $2 \theta_{\max }=45^{\circ}, R 1=0.034(F>$ $4 \sigma F)$ and $w R 2=0.091$ (all data, $g 1=0.050, g 2=1.934$; as defined above), max residual density: $7.6 \times 10^{2} \mathrm{e} \mathrm{nm}^{-3}$.

Data of both discussed structures were collected from a rapidly cooled oil-coated crystal on a Stoe-Siemens AED using graphitemonochromated Mo-K $\alpha$ radiation $(\lambda=71.073 \mathrm{pm})$. The structures were solved by Direct Methods. ${ }^{13}$ All non-hydrogen atoms were refined anisotropically on $\left(F^{2}\right) .{ }^{14}$ The uncoordinated thf molecule in 1 was refined as a rigid group with isotropical displacement parameters. Refinement of the Flack- $x$-parameter ${ }^{15}[x=-0.04(4)$ where $x=0$ for the correct absolute structure and +1 for the inverted structure] confirmed the absolute structure of $\mathbf{1}$. The crystal structure of $\mathbf{1}$ was successfully refined as a twin with a twinning factor $\mathbf{B}$ of $0.545(5) .{ }^{16} \mathrm{~A}$ semiempirical absorption correction with $357 \psi$-scans was applied on the structure of $\mathbf{2}$. Atomic coordinates, bond lengths and angles, and thermal parameters have been deposited at the Cambridge Crystallographic Data Centre. See Notice to the Authors, Issue No. 1. which are often used as tridentate monoanionic ligands. ${ }^{7,8}$ In contrast to the structure of $\left[\mathrm{Li}(12 \text {-crown- } 4)_{2}\right]\left[\mathrm{Ge}\left(\mathrm{SiMe}_{3}\right)_{3}\right]$ where the alkali metal is solvent separated from the germanium atom, ${ }^{11}$ in 1 the sodium atom is separated from the germanium atom through the pyrazol substituents, forming a contact ion pair. The crystal structure of 1 also contains an uncoordinated thf molecule, which is disordered on the three-fold axis.

2 Crystallizes as a dimer (Fig. 2). $\neq$ The structure can be interpreted as a twelve-membered ring system where two tin and two sodium atoms are connected via four pyrazolyl functions. Two of the three pyrazol substituents at the tin atom are bridging to a sodium atom while one is terminal. Furthermore the sodium atoms are coordinated by two thf molecules and one neutral pyrazol molecule. All Sn-N distances are in the same range [Sn(1)-N(1) 217.0(3), Sn(1)$\mathrm{N}(3) 216.0(3)$ and $\mathrm{Sn}(1)-\mathrm{N}(5)$ 217.6(4) pm]. Because the pyrazolyl rings are planar, the nitrogen donor electron pairs

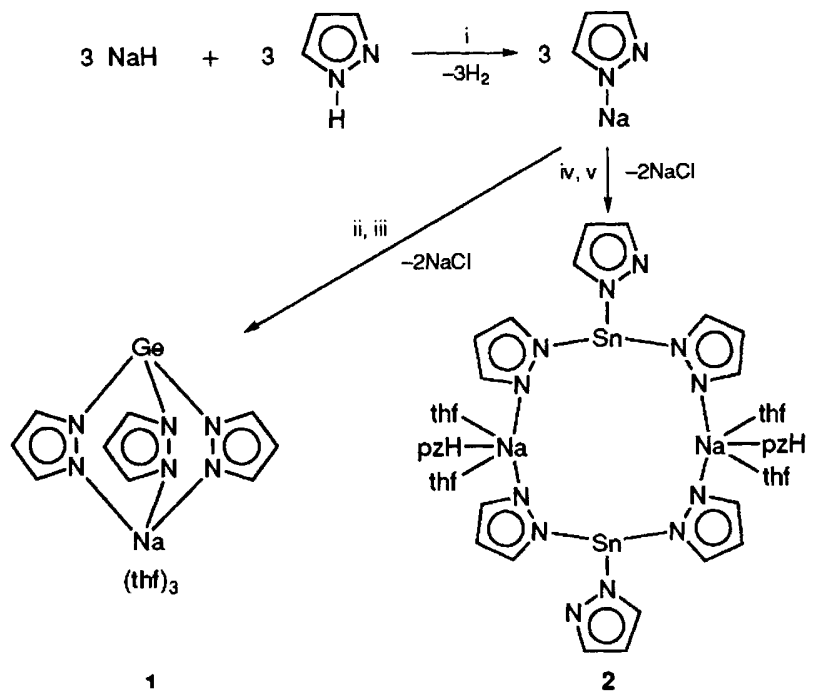

Scheme 1 Reagents and conditions: i, toluene, $25^{\circ} \mathrm{C} ; \mathrm{ii}, \mathrm{GeCl}_{2} \cdot$ dioxan, thf, $-78^{\circ} \mathrm{C}$; iii, $n$-hexane; iv, $\mathrm{SnCl}_{2}$, thf, $-78^{\circ} \mathrm{C}$; v, $n$-hexane

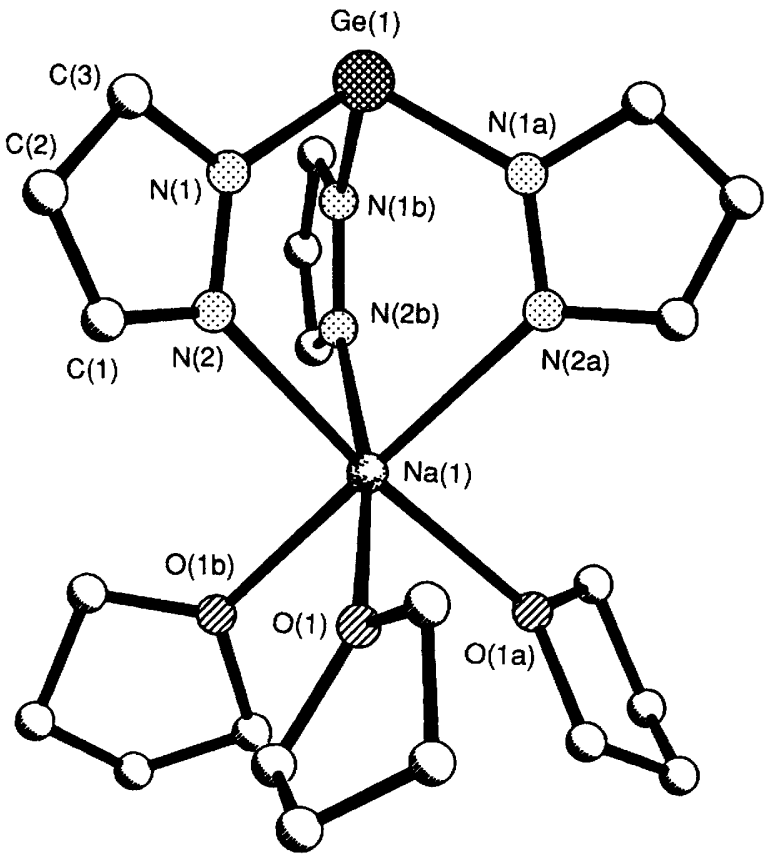

Fig. 1 X-Ray structure of 1 . The uncoordinated thf molecule has been omitted for clarity. Selected distances (pm) and angles: Ge(1)-N(1) 196.5(6), $\mathrm{Na}(1)-\mathrm{N}(2)$ 243.9(6); $\mathrm{N}(1)-\mathrm{Ge}(1)-\mathrm{N}(1 \mathrm{a})$ 96.2(2), $\mathrm{N}(2)-$ $\mathrm{Na}(1)-\mathrm{N}(2 \mathrm{a}) 82.9(2)$. 




Fig. 2 X-Ray structure of 2 . Selected distances $(\mathrm{pm})$ and angles $\left({ }^{\circ}\right)$ : $\mathrm{Sn}(1)-\mathrm{N}(1)$ 217.0(3), Sn(1)-N(3) 216.0(3), Sn(1)-N(5) 217.6(4), $\mathrm{Na}(1)-\mathrm{N}(2)$ 243.9(4), Na(1)-N(4a) 239.0(4), Na(1)-N(7) 245.1(4); $\mathrm{N}(1)-\mathrm{Sn}(1)-\mathrm{N}(3)$ 86.4(1), N(1)-Sn(1)-N(5) 86.8(1), N(3)-Sn(1)$\mathrm{N}(5) 88.9(1), \mathrm{N}(2)-\mathrm{Na}(1)-\mathrm{N}(4 \mathrm{a})$ 103.3(1).

are forced to be syn-periplanar to the $\mathrm{E}$ atom $(\mathrm{E}=\mathrm{Ge}, \mathrm{Sn})$. Consequently, the more acute $\mathrm{N}-\mathrm{E}-\mathrm{N}$ angle in $2(\mathrm{E}=\mathrm{Sn}$, $\left.86.4-88.9^{\circ}\right)$ than in $\mathbf{1}\left(\mathrm{E}=\mathrm{Ge}, 96.2^{\circ}\right)$ should result in stronger lone pair-lone pair repulsion between the nitrogen atoms. This may then result in the pyrazolyl rings of 2 twisting to lessen this repulsion. So the bis-pyrazolyl groups will be forced into a conformation in which they can no longer chelate effectively but instead prefer to bridge two metal centres. In 1 the wider grip of the $\left[(\mathrm{pz})_{3} \mathrm{Ge}\right]^{-}$unit can accommodate the sodium atom, while the $\left[(\mathrm{pz})_{3} \mathrm{Sn}\right]^{-}$unit cannot. The $\left[(\mathrm{pz})_{3} \mathrm{Sn}\right]^{-}$anion of $\mathbf{2}$ is closer to a pyramidal structure than the corresponding $\left[(\mathrm{pz})_{3} \mathrm{Ge}\right]^{-}$anion in $\mathbf{1}$.

In contrast to $\left[\left(\mathrm{Bu}^{\mathrm{t} O}\right)_{3} \mathrm{E}\right]^{-}(\mathrm{E}=\mathrm{Ge}, \mathrm{Sn} \text { and } \mathrm{Pb})^{5}$ and to $\left[\left\{\mathrm{Ph}\left(\mathrm{Bu}^{t}\right) \mathrm{C}=\mathrm{N}\right\}_{3} \mathrm{E}\right]^{-}(\mathrm{E}=\mathrm{Sn}, \mathrm{Pb})^{12}$ twisting of the ligand along the E-N bond allows fine tuning of the 'grip' of the ligand. Transmetallation reactions of these complexes with metal halides should give mixed metal compounds of defined composition, by sodium halide elimination. This feature should give access to a vast number of mixed metal complexes containing central group 14 metal substituents separated from a variety of metals (i.e. alkaline, alkaline earth, lanthanides, etc.). It may also be interesting to see what coordination properties the mixed sodium-germanium complex 1 has towards soft acid centres such as platinum or mercury. This might prevent a route to hard-soft bimetallic reagents due to coordination site selective behaviour.

The authors gratefully acknowledge financial support from the Fonds der Chemischen Industrie and the Deutsche Forschungsgemeinschaft.

Received, 2nd July 1993; Com 3/03842D

\section{References}

1 D. Reed, D. Stalke and D. S. Wright, Angew. Chem., 1991, 103, 1539; Angew. Chem., Int. Ed. Engl., 1991, 30, 1459.

2 D. R. Armstrong, M. G. Davidson, D. Moncrieff, D. Stalke and D. S. Wright, J. Chem. Soc., Chem. Commun., 1992, 1413.

3 W. P. Neumann, Chem. Rev., 1991, 91, 311.

4 M. Veith, Angew. Chem., 1987, 99, 1; Angew. Chem., Int. Ed. Engl., 1987, 26, 1.

5 M. Veith, Chem. Rev., 1990, 90, 3.

6 A. Steiner and D. Stalke, J. Chem. Soc., Chem. Commun., 1993, 444.

7 S. Trofimenko, Prog. Inorg. Chem., 1986, 34, 115.

8 S. Trofimenko, Chem. Rev., 1993, 93, 943.

9 P. K. Byers, A. J. Canty and R. T. Honeyman, Adv. Organomet. Chem., 1992, 34, 1.

10 T. Kottke, D. Stalke, J. Appl. Cryst., 1993, 26, 615.

11 A. Heine, D. Stalke, Angew. Chem., in the press.

12 A. J. Edwards, M. A. Paver, P. R. Raithby, C. A. Rusell, A. Steiner, D. Stalke, D. S. Wright, Inorg. Chem., in the press.

13 G. M. Sheldrick, Acta Crystallogr., Sect. A., 1990, 46, 467.

14 G. M. Sheldrick, SHELXL-93 programme for crystal structure refinement, 1993, University of Göttingen.

15 H. D. Flack, Acta Crystallogr., Sect. A., 1983, 39, 876.

16 C. S. Pratt, B. A. Coyle and J. A. Ibers, J. Chem. Soc., 1971, 2146. 